\title{
SOBRE CONSTRUCCIONES FRAGMENTADAS
}

Gemma Herrero

0 . Es moneda de uso corriente en la investigación lingüística el empleo de términos aparentemente idénticos que, en realidad, se refieren a nociones y conceptos en modo alguno equivalentes.

Este hecho es el que se observa al constatar el uso como sinónimos de los términos fragmentos, construcciones fragmentadas y enunciados fragmentarios, lo que provoca serias confusiones y conduce, inevitablemente, a una grave ambigüedad.

Para solventar este inconveniente dedicaremos este trabajo al estudio de la construcción fragmentada (apartados 1, 2, 3), analizando después las diferencias que pueden establecerse entre ella y otras construcciones, en principio, bastante similares, pero no iguales (apartado 4).

1. Emplearemos la expresión construcción fragmentada al referirnos a secuencias como las siguientes:

- Pues mira, yo, desde por las mañanas, me quedo sola en casa. Los chicos no .......Mira, el pequeño tiene que ir hoy a .... este...Mi marido regresa por la noche.

- Y la residencia es perfecta. Tiene unas instalaciones estupendas. Hay una, una...Bueno, también el jardin es precioso, grandísimo.

- Pues estaba bastante precupada ¿no?, porque como ...no sé. Estuve todo el día preocupada y dando vueltas a lo mismo: que si iba a venir, que si no me iba a llamar, figúrate tú.

- Y entonces cogió y se largó sin decir nada. Yo es que ahora... ¡Bah!. ¡Todo el día contemplándole y luego se comporta así!.

El tipo de secuencias presentadas es propio de la lengua hablada, sobre todo en su modalidad coloquial, pero, -aunque con menor frecuencia - también se documenta en los registros formales y en la lengua estándar.

¿Qué ha de entenderse por construcción fragmentada?. Muy brevemente se podría definir como aquella secuencia inacabada, producida por anacoluto en el nivel oracional, pero parece necesario profundizar en su concepto y analizarla con más detalle. 
1.1. Efectivamente, la construcción fragmentada es el resultado de un proceso de anacoluto $^{1}$ que se origina en el nivel oracional; es decir, se produce una ruptura en la construcción de una oración, ya que se interrumpe su enunciación sin completarla, iniciando la emisión de otra secuencia con la que no se relaciona, ni siquiera en términos de coherencia textual. Es conveniente, además, destacar el nivel oracional en el que se origina el anacoluto que da lugar a la construcción fragmentada, para no confundir ésta con otras secuencias -producidas por anacoluto en un nivel lingüístico inferior, el de los constituyentes oracionales (vid. n.1)-, en las que existen desviaciones sintácticas internas (discordancias de género o número, uso inadecuado de preposiciones, relativos, desajustes en la referencia pronominal, etc.) que ocasionan enunciados aceptables en términos comunicativos, aunque sintácticamente no lo sean.

1.2. La construcción fragmentada, como consecuencia del proceso de anacoluto, que afecta al discurrir lineal del discurso, es una secuencia incompleta, inacabada, puesto que manifiesta la carencia de constituyentes que completen la construcción desde un punto de vista sintáctico, semántico y comunicativo. Apenas iniciada su enunciación, es abandonada (debido a una serie de factores que serán analizados más adelante), para seguir con otra secuencia con la que no mantiene coherencia sintáctica, cohesión semántica ni temática, ni relación de ningún tipo. El rasgo incompleto, inacabado que la caracteriza es evidente en todos los estratos lingüísticos:

- en el fonólogico: la construcción fragmentada presenta un patrón melódico inconcluso, puesto que faltan los tonemas finales que se requieren para que las unidades lingüísticas

\footnotetext{
1. Aceptamos el concepto de anacoluto propuesto por los autores que citamos a continuación. G.Mounin ( Diccionario de Lingiiística, Barcelona, Labor, 1979, p.14): "Figura mediante la cual parece que se abandona una construcción ya iniciada y se continúa con otra. En el caso más frecuente, en el comienzo de la oración se coloca una expansión delante de un elemento con el cual ésta no se encuentra vinculada".

J.Dubois et alii (Diccionario de lingüística, Madrid, Alianza Editorial, 1979, p.39): "Ruptura en la construcción de una oración".

F. Lázaro Carreter (Diccionario de términos filológicos, Madrid, Gredos, 1981, $3^{\text {a }}$ ed., $5^{\text {a }}$ reimp, p.41): "Abandono de la construcción sintáctica exigida por un período, para adoptar otra más acorde con lo que el hablante piensa en aquel momento, con olvido de la coherencia gramatical".

W. Abraham (Diccionario de terminología lingüística actual, Madrid, Gredos, 1981, pp.57-58): "Omisión de la continuación o conclusión de la oración inicial debido a distracción, excitación u olvido; en miembros aislados de la oración, anacoluto es la reasunción en otro caso".

La Real Academia Española (Diccionario de la lengua española, Madrid, Espasa-Calpe, 1984, 20ª ed., p.88): "Inconsecuencia en el régimen o en la construcción de una cláusula".

R. Cerdá et alii (Diccionario de linguiística, Madrid, Anaya, 1986, p.18): "Desviación sintáctica en el curso de la construcción oracional".

En Ma.J.Bedmar: "El anacoluto en la lengua hablada", en Estudios en memoria de de J.Fernández Sevilla y N.Marín López, Universidad de Granada, 1987, pp.56-79, se realiza un análisis detallado de este fenómeno; también en G.Herrero: "El anacoluto en el habla culta de Bogotá", en C.Hernández et alii (eds.):El español de América, I, Salamanca, Junta de Castilla y León, 1991, pp.505-517.
} 
constituyan un enunciado; consecuentemente, no se cumplen las funciones integradora y delimitadora de la entonación².

- en el sintáctico, ya que el abandono de la construcción iniciada supone la ausencia de los constituyentes requeridos para poder completar la estructura sintáctica de la secuencia considerada.

- en el semántico, puesto que no se pude establecer el significado global de la secuencia, disponiendo tan sólo de la parte expresa.

- en el comunicativo: la secuencia verbalizada no es una unidad comunicativa e informativa plena, ya que no goza de autonomía sintáctica y semántica, ni tampoco puede recibir interpretación comunicativa, aunque se la relacione con el contexto lingüístico previo o posterior, con el contexto extralingüístico ${ }^{3}$ o con la situación en la que se emite, por consiguiente no constituye enunciado ${ }^{4}$.

En definitiva, utilizamos la denominación construcción fragmentada, para denotar, en primer lugar, que ésta no puede ser reconocida ni aceptada como oración, frase, etc.(unidades sintácticas), puesto que carece de una estructura interna que permita reconocerla como tal; tampoco como enunciado ${ }^{5}$ (unidad comunicativa), ya que no posee independencia sintáctica, predicatividad, autosuficiencia significativa, ni siquiera integridad textual; en segundo lugar, para destacar que la ruptura que se produce origina una secuencia

2. A.Quilis: Fonética acústica de la lengua española, Madrid, Gredos, 1981, pp.384 y ss, sostiene que la forma de entonación es lo que da validez de enunciado a una palabra o grupo de palabras, ya que las integra y prepara para que formen un enunciado, a la vez que segmenta el discurso en un determinado número de unidades, delimitando los enunciados existentes.

3 . E.Coseriu: "Determinación y entorno", en Teoría del lenguaje y lingüística general, Madrid, Gredos, 1973, $3^{\text {a }}$ ed., pp.282-323, denomina a este tipo de contexto contexto empírico; en él se incluyen los conocimientos y la información consabida y compartida por los participantes en la comunicación, es decir, el estado de cosas objetivo conocido por los hablantes.

4. Denominamos enunciado a toda secuencia lingüística sintácticamente independiente, autónoma y autosuficiente, desde el punto de vista del significado, y que constituye una mínima unidad de comunicación. Este concepto es similar al que presentan otros autores bajo otras denominaciones: G.Rojo: Claúsulas y oraciones, Santiago de Compostela, Universidad, 1978, pp.24-26, considera enunciado a toda unidad caracterizada por su naturaleza predicativa o comunicativa, por carecer de relaciones sintagmáticas con elementos exteriores y por ser completa desde el punto de vista semántico. Por tanto, constituir o no enunciado es independiente de la estructura de la cadena en cuestión. J.M. Lope Blanch: "Unidades sintácticas. (Recapitulación)", R.F.E, LXI, Madrid, 1981, pp.29-63, utiliza el término cláusula en un sentido parecido: "Unidad de manifestación; es la expresión autónoma desde el punto de vista de la elocución", p.30. S.Gutiérrez Ordóñez: "¿Es necesario el concepto de oración?", R.S.E.L, 14.2, 1984, pp.245-260, define el enunciado como "Unidad lingüística y de comunicación compuesta por dos signos interrelacionados: el signo enunciativo y el esquema sintagmático", pp.251-253.

5. L.Cortés Rodríguez, Sintaxis del coloquio. Aproximación sociolingüística, Salamanca, Universidad, 1986, considera que estas secuencias son enunciados oracionales inacabados, ya que utiliza el término enunciado con un valor distinto al que acabamos de exponer, y bastante próximo al que presentan algunos autores distribucionalistas - cualquier extensión de habla, pronunciada por una persona, antes y después del cual hay un silencio (Vid.Z.Harris, Methods in Structural Linguistics, Chicago, University of Chicago Press, 1951, p.14).Estos autores no consideran la predicatividad y la autosuficiencia semántica como rasgos distintivos y necesarios para que exista el enunciado. 
fragmentaria, inacabada o incompleta, que, en muchos casos, no puede ser identificada, sobre todo si la construcción fragmentada es muy breve.

Es importante incidir en la importancia conjunta de ambos aspectos para no inducir a posibles errores de interpretación ${ }^{6}$.

2. Establecer una clasificación tipológica de la construcción fragmentada entraña una evidente dificultad, teniendo en cuenta los problemas que hay para identificar el tipo de unidad sintáctica que pudiera constituir la parte expresa, ya que ésta presenta una extensión sumamente variable -puede reducirse a una sola palabra o ampliarse a secuencias muy complejas- ; además, a esta dificultad se añaden las relativas al nivel de análisis lingüístico al que corresponde la construcción fragmentada, y a la actuación del principio de recursividad. Por otra parte, tampoco parece que sea absolutamente necesario realizar una clasificación minuciosa, si se afirma que tales secuencias no constituyen unidades comunicativas plenas, no son enunciados.

Teniendo en cuenta estas limitaciones, estableceremos una clasificación esquemática que pueda dar cuenta del mayor número posible de secuencias. Para ello consideraremos exclusivamente la construcción fragmentada, sin marcar diferencias entre las construcciones aisladas (unidades simples) y las incluidas en otras secuencias más complejas (unidades complejas) ${ }^{7}$. En consecuencia, distinguimos tres tipos fundamentales:

2.1. Construcciones fragmentadas en las que, al menos, se hace explícito el núcleo del sintagma verbal -en algunos casos se manifiestan, además, otros elementos-, pero faltan términos oracionales que completen la estructura sintáctica de la secuencia, es decir, no aparecen formulados constituyentes obligatorios, exigidos por el verbo (los complementos regidos o subcategorizados ${ }^{8}$ ):

- Y la residencia es perfecta. Tiene unas instalaciones estupendas. Hay una, una...Bueno, también el jardin es precioso, grandísimo.

- Su forma de portarse conmigo lo único que está demostrando es que su trabajo es, es..estoo.. está de muy mal humor, de muy mal humor y yo ya no se qué hacer.

\footnotetext{
6. Como se verá más adelante (4.1), ciertos autores emplean el término enunciados fragmentarios para referirse a enunciados formalmente incompletos, que presentan autonomía semántica e integridad textual.

7. La unidad simple está formada exclusivamente por elementos pertenecientes a tipos inferiores, por tanto no contiene en su interior unidades de su mismo tipo. La unidad compleja es aquella en la que, en virtud del mecanismo de recursividad, uno o más de sus elementos funcionales es una secuencia perteneciente a su mismo tipo (Vid. G.Rojo: Aspectos básicos de sintaxis funcional, Málaga, Librería Agora, 1983, pp.72-73. G.Rojo y T.Jiménez Juliá: Fundamentos del análisis sintáctico funcional, Santiago de Compostela, Universidad, 1989, pp.105-107).

8. M.L.Hernanz y J.M.Brucart: La sintaxis, Barcelona, Editorial Crítica, 1987, pp.232-238.
} 
- Unos discos geniales tenían, de muy buenos músicos. Y después conocí a otros, que ahora son amigos también, que tenían una...., les encantaba la música, compraban un montón de discos.

- Es una ciudad hermosa, como todas las ciudades capitales o principales de Europa, pero ahora encontramos...., es como los países donde se nota la tristeza de la gente desde que uno pisa tierra.

2.2. Construcciones fragmentadas sin realización fonológica del núcleo verbal: se hacen explícitos constituyentes oracionales aislados, cuya función sintáctica no puede ser precisada - excepto casos aislados, por ejemplo, si la parte expresa es un pronombre personal sujeto-:

- Así poco más o menos estuvimos toda la noche y él, él... bueno, yo no entendía nada de lo que estaba pasando.

- Pues mi marido no ha sido un problema porque el niño, el niño..., entonces yo por la noche, pues ordeno un poco la casa cuando puedo.

- Es que con la adaptación..., lo que pasa es que ahora, en este caso lo mejor es producir la tirada de una sola vez.

- Desde luego has andado una barbaridad si vienes de tu casa. Desde la facultad deprisa.... ¡Desde luego, qué bruta eres, hija!

:2.3. Por último, el caso más escueto de construcciones fragmentadas se produce en secuencias coordinadas o subordinadas, al hacerse explícita tan sólo la conjunción coordinante o subordinante sin la presencia de los elementos que debe introducir:

- Eso sí que me dió mucho coraje porque..... Así que me levanté, pedí el turno y dije todo lo que me pareció.

- Las calles transversales son prácticamente callejas que se unen con las avenidas principales pero... y también hay paredes sucias en edificios bonitos.

- Que no iba a ir al concierto tarde te lo dije el otro día cuando... ¡Y encima eres tú la que te enfadas, después de que te he avisado!.

3. Para llegar a comprender la naturaleza de la construcción fragmentada es conveniente determinar las circunstancias y factores de todo tipo -lingüísticos, extralingüísticos, etc.- que la originan.

En general, se señalan como agentes principales:

a/ circunstancias físicas que afectan al contexto y situación comunicativa: la rapidez del coloquio, la actualización de la situación comunicativa, la alternancia de turnos en el intercambio comunicativo, etc. 
b/factores psíquicos, relativos a los hablantes: espontaneidad, inconsciencia, rapidez del pensamiento, olvido de formas lingüísticas, distracciones, etc.

c/condicionamientos lingüísticos: competencia lingüística insuficiente y limitada, lo que implica un desconocimiento parcial de los distintos niveles de la lengua.

Más detalladamente se pueden ejemplificar los siguientes:

3.1. La interacción comunicativa ocasiona, en bastantes casos, la participación activa del receptor $^{9}$, que sale al paso de la información de su interlocutor, interrumpiendo su emisión y adelantándose a su propio turno de habla, ya sea mediante secuencias o fórmulas de uso fático que confirman el proceso de recepción, o mediante matizaciones, explicaciones o preguntas directas dirigidas al hablante; esta circunstancia, en consecuencia, origina una construcción fragmentada, ya que el hablante, interrumpido por su interlocutor, abandona la secuencia iniciada, para comenzar otra nueva:

- A: Fue el trece de Abril. Teníamos al niño en cama porque el día de antes......

B: El niño pequeño ¿no?.

A: Sí, el pequeño, el mayor estaba con la abuela. Entonces empezaron unos truenos terribles, una tormenta de las de verdad.

- A: No he conseguido convencerle de que me dé la dirección. Así no puedo mandar la....

B: Después.

A: Vale, vale.

3.2. Otro factor desencadenante de la construcción fragmentada, muy relacionado con el intercambio comunicativo y con la cooperación y conexión interlocutiva, consiste en la repetición automática ${ }^{10}$ de ciertas partes de la emisión anterior del interlocutor, no conectadas con la respuesta que se va a dar a continuación. En consecuencia, una vez reproducidas las palabras previas -funcionan exclusivamente como marcas de interacción-, son abandonadas sin haber constituido un verdadero enunciado, continuando después con la verdadera respuesta:

- A: ¿Y es muy costosa la adaptación?

B: La adaptación..la adaptación... Lo que pasa es que es mucho más fácil producir la unidad de una sola vez.

- A: Primero empezaste en económicas y luego lo dejaste ¿no?

9. C.Hernández: "El español popular y su adaptación literaria", Linguistica Antverpiensia, XXIII, 1989, pp.83100 , considera que este es uno de los factores que sirven para caracterizar de modo determinante la lengua coloquial. Su actuación en el nivel sintáctico da lugar a mensajes entrecortados y fragmentarios.

10. Emma Martinell en su trabajo Encadenamiento por repetición en la estructura coloquial, (resumen de tesis doctoral)Barcelona, 1974, señala que la repetición o encadenamiento formal es el testimonio de que se ha recibido y comprendido correctamente el mensaje. 
B: Sí, en.. en económicas... No, acabé COU y me fui a Francia con una beca.

3.3. Determinados ruidos, interferencias e, incluso, la súbita aparición de un nuevo participante en el acto comunicativo solapan y truncan la emisión iniciada, motivando una construcción fragmentada:

- Esta semana no he podido estudiar nada. El lunes y el martes tuve .... ¡Pero Pacoo! ¡Esa música, que no hay quién se entienda! En esta casa, ya ves, ¡no se puede estudiar!.

- A: ¿Pero tú no te habías enterado?

B: No, no, no sabía que se habían separado. No sé. A lo mejor al ver que estaban....

C (nuevo interlocutor): ¿Qué tal, Elena? ¡Cuánto tiempo sin verte!

A: Quedé con ella ayer para que viniera a casa.

3.4. La actualización e inmediatez del discurso obliga al hablante a producir sus emisiones de forma espontánea, rápida y totalmente improvisada; por ello es frecuente que la idea general que se va a comunicar no esté suficientemente elaborada, sobre todo en términos sintácticos. Esta circunstancia ocasiona numerosas vacilaciones e imprecisiones en la formulación del mensaje: la fluidez comunicativa se va resintiendo hasta el punto de renunciar a concluir el incipiente mensaje, lo que origina una secuencia fragmentada:

- Y todo es así. Se les va y se les.... Se les va al.. Y yo creo que les .... Al final crecen un poco insensibles a todo.

- No, si no voy a poder; creo que por la mañana voy a... a lo de... a lo de, de....eso de la.... bueno, no me esperéis.

3.5. En circunstancias concretas el olvido o, incluso, el desconocimiento del término exacto que se quiere verbalizar dan lugar a construcciones fragmentadas, ya que el hablante, al no saber cómo continuar la secuencia iniciada, la abandona y prosigue con otra:

- Las mesas eran como estilo....estilo lo que hubo una época aquí que se llamaba....que uno se paraba y recitaba. No me acuerdo.

- Trabaja ahora en...en..el....la oficina esta de... Bueno, ¿Cómo narices se llama?.

3.6. En bastantes casos la aparición súbita de información nueva o remática (surgida por asociación de ideas, porque un término evoque recuerdos y circunstancias que el hablante hace explícitos, o porque este quiera ampliar, matizar o explicar su emisión anterior o las 
circunstancias concretas que la rodean), no conectada sintáctica ni comunicativamente con la secuencia previa, ocasiona la interrupción y el posterior abandono de la construcción iniciada:

- Entonces me enfadé un montón porque.... ya sabes que yo no necesito ni un pelo para enfadarme por lo que sea, que estoy muy sentida últimamente, después de lo de Alfredo,...Bueno, pues la canté las cuarenta.

- Estábamos esperando, al final llegaron por fin todos y nos fuimos para la piscina. El primo de Marita traía a... que, por cierto, ¿te has fijado lo buenísimo que se ha puesto este año?. El año pasado no estaba así ni con mucho ¡Si parecía un pobrecito, que no se comía nada!. Después fuimos al bar ese del jardin grande y a las doce, a casa.

Los factores citados son los principales inductores de la construcción fragmentada y, como consecuencia, del cambio posterior en la estrategia de codificación del mensaje; no obstante, pueden considerarse aún otros que actúan ocasionalmente, tales como el eufemismo y el tabú. La emisión resulta inacabada porque el hablante no hace explícita, vela una realidad conocida por él, pero que no está suficientemente clara para el oyente, por lo que no puede ser interpretada ni contextual ni situacionalmente.

4. Una vez analizada la construcción fragmentada, parece conveniente diferenciarla de otras construcciones afines, a primera vista, pero que presentan propiedades y rasgos diferentes. Las secuencias estudiadas son las siguientes:

4.1. Enunciados fragmentarios y fragmentos.

4.2. Construcciones suspendidas.

4.3. Enunciados coemitidos, concluidos gracias a la participación del oyente o a la intervención del emisor en su nuevo turno de habla.

4.4. Enunciados finalmente acabados como consecuencia de un proceso de recodificación del mensaje.

4.1. La expresión enunciados fragmentarios es utilizada por algunos autores para referirse a ciertos enunciados incompletos desde el punto de vista sintáctico -faltan elementos requeridos por la sintaxis formal-, pero no desde la perspectiva semántica y comunicativa -son verdaderos enunciados-.

J.Dubsky ${ }^{11}$ denomina de este modo a determinadas oraciones unimembres que resultan formalmente incompletas debido al carácter emocional del enunciado.

L.Cortés ${ }^{12}$ lo utiliza para señalar los enunciados elípticos con integridad contextual.

11. Introducción a la estilística de la lengua, Santiago de Cuba, Universidad de Oriente, 1970, pp.52-53.

12 . Sintaxis... 
A.Vigara ${ }^{13}$, aunque se hace eco del término enunciados fragmentarios, intenta evitar el equívoco que suscita esta expresión; por ello, emplea el sintagma enunciados expresivos esquemáticos para designar aquellas secuencias en las que se ha producido una elipsis formal que origina una condensación expresiva de sus constituyentes, pero, a pesar de ello, "su sentido es completo y perfectamente comprendido en la comunicación".

R.Simone ${ }^{14}$ considera que la expresión fragmentos de enunciado es un término adecuado para denotar ciertos residuos de estructuras que, como tales, no se pueden analizar de forma completa con las técnicas sintácticas normales. Distingue tres tipos: 1/ Exclamaciones; 2/ Fragmentos que actúan como respuesta en una conversación; 3/ Intercalaciones (elementos con F.Fática) utilizadas para dividir momentos distintos en un enunciado, o para cubrir pausas de exploración.

Con este mismo sentido se usa el término fragmentos en la corriente generativa: estructuras que carecen de un verbo en forma personal y, a veces, de otros constituyentes oracionales que pueden ser restituidos por distintas vías: gramaticales o textuales ${ }^{15}$. La concepción de los fragmentos varía según los autores; para unos los fragmentos son oraciones completas que presentan como principal característica la de llevar elidida la mayor parte de sus componentes. Por ello defienden que los fragmentos poseen características sintácticas ${ }^{16}$. Sin embargo, otros autores ${ }^{17}$ creen que no es adecuado interpretar todo tipo de fragmentos como oraciones completas, ya que, por una parte, se usa de forma demasiado laxa el concepto de categoría vacía, lo que supone complicar innecesariamente el conjunto de principios sintácticos de la gramática; por otra, la interpretación semántica de las categorías vacías sigue siendo cometido de la gramática del discurso.

En suma los fragmentos o enunciados fragmentarios son secuencias en las que no aparecen explícitos determinados constituyentes oracionales (en general, el verbo), lo que dificulta su interpretación sintáctica. Sin embargo, su interpretación semántica y pragmática (por tanto, su consideración como enunciados) se efectúa fácilmente considerando diversos factores:

a/ el contexto lingüístico previo:

- A: ¿A quién has saludado?

13. Morfosintaxis del español coloquial, Madrid, Gredos, 1992, pp.109-114.

14. Fundamentos de linguíística, Barcelona, Ariel, 1993, pp.200-202.

15. Realmente el concepto de fragmento coincide con distintas denominaciones empleadas por diversos autores: frase nominal (E.Benveniste: "La phrase nominal", en Problèmes de linguistique générale, I, Paris, Gallimard, 1966, pp.151-167; R.Navas Ruiz: "Pausa, base verbal y grado cero", R.F.E, XLV, 1962, pp.273-284; C.Hernández: Gramática funcional del español, Madrid, Gredos, 1984); frase (J.Alcina y J.M.Blecua: Gramática española, Barcelona, Ariel, 1975); oración sincopada (M.Seco: "La lengua coloquial: 'Entre visillos', de Carmen Martín Gaite, en El comentario de textos, 1, Madrid, Castalia, 1973, pp.357-375); oración unimembre (en la tradición gramatical española), etc.

16. J.L.Morgan: "Sentence Fragments and the Notion Sentence", en B. Kachru et alii (eds): Issues in Linguistics: Papers in Honor of H. and R. Kahane, Urbana, University of Illinois Press, 1973, pp.719-751; M.L.Hernanz: "Oració i fragments: vers una definició conjunta", Els Marges, 13, 1978, pp.88-102; "Oració y fragments: solució transformacional o interpretativa?", Els Marges, 15, 1979, pp.81-93.

17. J.M.Brucart: La elisión sintáctica en español, Barcelona, Bellaterra, UAB, 1987. 
B: A María.

b/ la situación comunicativa en la que se emiten:

- (En un taxi): ¡A la estación de autobuses!.

c/ la entonación enfática ${ }^{18}$ que poseen:

- ¡La mujer de Pedro y su amante!.

Como puede observarse, las semejanzas entre las construcciones fragmentadas y los fragmentos son, exclusivamente, terminológicas. Las diferencias resultan bastante evidentes: desde un punto de vista fonológico, los fragmentos poseen una entonación cerrada, con tonema final generalmente descendente que cumple las funciones integradora y delimitadora (vid. n.2), permitiendo su interpretación como enunciados. Sintácticamente, puede determinarse qué tipo de unidad constituyen las unidades que aparecen explícitas: oración, sintagma nominal, prepositivo, adverbial, etc. ${ }^{19}$. Por otra parte, están dotados de autonomía significativa, puesto que reciben interpretación semántica, ya sea por vía contextual, situacional o gramatical. Finalmente, los fragmentos son unidades textuales, constituyen enunciado.

4.2. La oración suspendida, en palabras de Manuel $\mathrm{Seco}^{20}$, "se presenta 'incompleta' desde el punto de vista de la sintaxis formal, pero ello no impide que la comunicación sea perfecta. El hablante omite todo lo que ya está sugerido por sus restantes palabras. Esta eliminación de elementos no necesarios, o menos necesarios, no se explica por pura economía, sino por el relieve singular que tiene para el hablante una parte del mensaje, la que con más urgencia desea transmitir al oyente y que le lleva a desdeñar como superfluo todo lo demás".

Antonio Narbona ${ }^{21}$ insiste en la idea de que las construcciones suspendidas, en lugar de considerarse como inacabadas, "han de verse completas en cuanto suspendidas", puesto que la suspensión obedece a una finalidad expresiva del hablante que abre la puerta a significados múltiples (intensificación elativa, potenciación afectiva, etc.) o, en otros casos, está motivada por la vinculación de los enunciados a la situación comunicativa en la que se

\footnotetext{
18. Según S.Skydsgaard: La combinatoria sintáctica del infinitivo en español, Madrid, Castalia, 1977, pp.11251126, en virtud del papel segmentador y enfático de la entonación marcada, o entonación de elipsis, pueden funcionar como unidades autónomas -constituyendo, por tanto, enunciado- constituyentes que, con una entonación neutra, requerirían la presencia de un verbo y funcionarían como componentes oracionales.

19. Como ya se ha indicado, la determinación de la unidad sintáctica de que se trate varía en función de la interpretación que se realice; así, algunos autores los consideran como componentes de una oración con algunos constituyentes tácitos (categorías vacías); otros los consideran, básicamente, unidades textuales, por lo que se eximen de realizar su interpretación sintáctica; sin embargo otros autores que separan de forma tajante la perspectiva sintáctica y la comunicativa consideran tan sólo la forma y estructura interna del fragmento, a la hora de establecer qué tipo de unidad sintáctica es éste (G.Rojo y T.Jiménez Juliá: Fundamentos....).

20. "La lengua coloquial...

21. "Problemas de sintaxis coloquial andaluza", RSEL, 16.2, Madrid, 1986, pp.231-275.
} 
emiten, lo que permite no verbalizar información que se considera innecesaria por ser evidente o ya conocida.

Comparando las secuencias fragmentadas, anteriormente citadas, con cualquiera de las suspendidas que, seguidamente, se presentan, pueden establecerse las semejanzas y diferencias entre ellas:

- A: No se van a ir de aquí. Ya lo verás.

B: Si les echamos nosotros algo de pasta a lo mejor...

- ¡Con decirle que lo entalegaron porque casi mata a su padre a cuchillazos...

- A: ¡Menos mal que hemos llegado ya! Vamos a la puerta de internacionales, que estarán mis padres esperándonos.

B: ¿Y las maletas.....

Ambas construcciones comparten dos rasgos:

Desde un punto de vista sintáctico muy estricto, carecen de los términos necesarios para completar formalmente la construcción.

Las dos presentan un patrón entonativo inconcluso, debido a la brusca interrupción de una, y a la suspensión de la otra. De todos modos la secuencia suspendida posee una especial línea melódica, -claramente diferente a la de la construcción fragmentada, puesto que suele presentar una marcada anticadencia como base expresiva al final de la rama tensiva- que contribuye a hacer interpretable la parte no expresa.

Las diferencias se manifiestan en el nivel semántico y en el plano comunicativo.

Como ya se ha señalado, la construcción fragmentada es una secuencia semánticamente incompleta, puesto que no se pude establecer el significado global de la secuencia, disponiendo tan sólo de la parte expresa; tampoco su vinculación con el contexto linguiístico previo, con el contexto extralingüístico o con la situación comunicativa en que se emite permite asignarle una interpretación semántica. Por el contrario, la construcción suspendida posee un significado cerrado y acabado, por mínimo que sea.

Además, la secuencia fragmentada no constituye enunciado (vid.supra.1.2). La construcción suspendida, sin embargo, es una unidad informativa plena, ya que transmite un mensaje válido y aceptable en términos comunicativos, en el que aparecen explícitos los términos y constituyentes focalizados por el hablante, e implícitos, pero a la vez, sugeridos y potenciados expresivamente por medio de la suspensión y la anticadencia, los restantes elementos. Para realizar su interpretación su como enunciado, es decisivo, por tanto, establecer su relación con la situación, con el contexto lingüístico anterior, con el contexto extralingüístico y con la entonación peculiar que posee.

4.3. Inicialmente las construcciones que analizaremos a continuación parecen ser secuencias fragmentadas, ya que se interrumpe momentáneamente su emisión. No obstante, 
la colaboración del oyente o la propia intervención del hablante en su nuevo turno de habla consiguen que la secuencia resultante de la coemisión constituya un enunciado.

Estas construcciones, por tanto, se originan en circunstancias bien determinadas:

4.3.1. En el transcurso del intercambio comunicativo es frecuente que el interlocutor se anticipe a su turno de habla, interrumpiendo la emisión del hablante, con el fin de matizar, precisar, o pedir explicaciones sobre lo ya emitido, o bien para confirmar mediante fórmulas de uso fático que la conexión interlocutiva se mantiene e, incluso, para evitar que el emisor continúe hablando. En algunos casos, el hablante abandona la secuencia que ha sido interrumpida por su interlocutor e inicia otra nueva, originando, de este modo, una construcción fragmentada (vid.supra 3.1). Pero es frecuente que el emisor sea consciente de la interrupción que ha sufrido e intente, por todos los medios, defender y recuperar de nuevo su turno de habla para finalizar la oración comenzada ${ }^{22}$. El resultado de este proceso es una secuencia (emitida en dos o más turnos consecutivos) que constituye enunciado:

- A: Nos pusimos a la cola para guardar....

B: ...pero estabas con María ¿no?

A: sí, sí, con María....para.. para guardarles la vez a mis padres, que se estaban tomando una café antes de entrar a ver la película .

- A: Bueno, entonces, si no piensas presentarte al examen, pues tienes que...

B: ..mira, no te pongas pesadita

A: .. tienes que notificarlo para que no te corra convocatoria. Y no me pongo pesada, que es por tí.

Es frecuente que en la nueva intervención del hablante se produzcan repeticiones, para manifestar la cohesión sintáctica y semántica con la parte anteriormente expresada. Asimismo el hablante puede no respetar tampoco el turno anticipado del receptor, interrumpiéndole a su vez, lo que provoca series sucesivas de construcciones fragmentadas y oraciones completas en dos turnos del mismo emisor o bien, sólo de oraciones completas:

- A: Los estaba haciendo con la misma salsa que hizo...

B:... ¿pero estaba.....

A: ...la salsa que hizo para las almejas.

B: Bueno, pero por fin ¿qué había de comida?

22. En las teorías pragmáticas sobre el análisis del discurso y de la conversación se establece la existencia de unidades estructuradoras de turno, que suelen coincidir con unidades sintácticas mínimas que forman enunciados (S.C.Levinson: Pragmática, Barcelona, Teide, 1989, p.284). Por ello es lógico que el hablante intente recuperar su turno y finalizar su mensaje, ya que el final de éste se convierte en el lugar pertinente de transición, lo que indica que justamente ahí se puede producir la alternancia de locutores. 
4.3.2. Otras veces, el receptor, previendo el posible desarrollo de la secuencia que está siendo emitida por el hablante, se anticipa a su turno de habla e interrumpe al emisor con la única finalidad de colaborar con él en la consecución del enunciado:

- A: ¡No veas!. Fue sacar las chuletas a la mesa y todos nos pusimos a comer como si fuéramos....

B: ...caníbales, por lo menos.

A: Sí, sí, caníbales.

- A: Tropieza uno con profesionales que son tal vez quien más.

B: ...errores cometen.

En otras ocasiones, el receptor, ante las vacilaciones y titubeos del emisor, asume su propio turno de habla (la detención del fluido comunicativo se interpreta en muchos casos como indicador de cambio de turno) y coopera con el hablante, brindándole las palabras o la parte del mensaje que éste no logra verbalizar:

- A: Es horrible para dormir ahí. Las camas individuales que tiene son muy, muy...

B: ...estrechas, incómodas.

A: Sí, muy incómodas y estrechas, todo.

En suma, estas oraciones son el resultado de un proceso de coemisión: el receptor interviene no en calidad de nuevo emisor -dada la alternancia de turnos en la comunicación-, para expresar su propio punto de vista, como sucede en las secuencias anteriores (4.3.1). En estas secuencias el receptor asume las palabras de su interlocutor y coopera con él en la producción de una secuencia unitaria. Para A.Vigara ${ }^{23}$, el hecho de "completar con las propias palabras el pensamiento del hablante es una de las formas más curiosas que reviste la cooperación en la actividad interlocutiva alternante" o cooperación fática. También W.Beinhauer ${ }^{24}$ considera que la emisión conjunta de hablante y oyente para producir un conjunto oracional homogéneo, una construcción unitaria, es un hecho frecuente que se constata en el encadenamiento entre habla y réplica.

Las diferencias entre estas secuencias (4.3) y las fragmentadas son evidentes en todos los niveles lingüísticos: las oraciones coemitidas poseen un patrón entonativo cerrado que delimita el enunciado que forman; por otra parte, se puede determinar, claramente, qué tipo de unidad sintáctica es la resultante de la coemisión: una oración, en general ${ }^{25}$; forman un

23. Morfosintaxis..., p.382.

24. El español coloquial, Madrid, Gredos, 1978, $3^{\text {a }}$ ed., p.192.

25 . Lógicamente, hay que tener en cuenta que en algunos casos no puede hablarse de oración, en términos estrictamente sintácticos, ya que el cambio de turno emisor-receptor provoca cambios de perspectiva en la formulación del enunciado, por lo que la concordancia sujeto-verbo (entre otros posibles hechos) no se mantiene, al adaptarse a las nuevas condiciones de enunciación:

- A: El viernes dió las notas y nos pusimos a gritar como...

B: ...como si estuviéseis locos. 
conjunto significativo autosuficiente y, finalmente, pueden ser consideradas enunciado, ya que presentan las características propias de éste.

4.4. Enunciados finalmente acabados como consecuencia de un proceso de recodificación del mensaje.

Debido a la actualización, espontaneidad, improvisación, etc. de la conversación, es frecuente que el mensaje sea recodificado, para conseguir una secuencia más adecuada con lo que el emisor desea expresar.

Unas veces el proceso de recodificación del mensaje está motivado por factores de carácter gramatical. En el momento de la enunciación el hablante, al ser consciente de que está produciendo un mensaje en el que existen incorrecciones o inadecuaciones -de tipo morfosintáctico o semántico- con lo que piensa decir a continuación, introduce las modificaciones precisas para lograr que la secuencia resulte gramaticalmente correcta:

- Mira Juan, tu padre está muy poco contento en.. en... con tus notas.

- No, si también aquí existe una asociacion que ...bueno, existía hasta hace muy poco una asociación que defendía a los animales.

La recodificación, en este caso, es un tipo de autocorrección o rectificación morfosintáctica o semántica, que se produce de forma diversa: modificando la flexión nominal o verbal, estableciendo la concordancia apropiada, cambiando el tiempo o modo verbal, las preposiciones o conjunciones, el término inexacto, etc. No hay que olvidar que estos enunciados se originan en el habla, pertenecen a la actuación lingüística; en la realización escrita de la lengua la rectificación también se produce, aunque no sea visible para el lector-receptor: siempre cabe la posibilidad de anular la parte inadecuada suprimiéndola del texto. Sin embargo en el habla tal omisión es imposible, pero la rectificación puede realizarse aportando los elementos adecuados. El oyente recibe e interpreta la secuencia emitida como un todo unitario, haciendo abstracción y excluyendo los elementos inapropiados. Por ello no parece conveniente denominar a estas construcciones enunciados oracionales incorrectos, como hace L.Cortés Rodríguez ${ }^{26}$, adoptando, desde nuestro punto de vista, un criterio excesivamente formal y, por tanto, alejado de la realidad del discurso conversacional. Si se habla de rectificación -y él lo hace- hay que considerar la totalidad de la secuencia, y, en concreto la parte rectificada, no sólamente la parte "incorrecta" (utilizada por él para denominarla).

En otros casos la recodificación obedece, básicamente, a factores de tipo comunicativo. El hablante considera que la parte del mensaje que ha sido verbalizada no es suficientemente

De todas formas, aunque se trate una oración agramatical, es aceptable en términos comunicativos, por lo que constituye enunciado.

26. Sintaxis..., pp.51-54. L.Cortés, siguiendo a I.B.Robach: Etude sociolinguistique de la segmentation syntaxique du français parlé, CWK, Lund, 1974, considera cuatro faltas motivadoras de enunciados oracionales incorrectos, entre ellas destaca la rectificación sintáctica. 
informativa, porque al receptor le faltan datos (del contexto extralingüístico o empírico) necesarios para poder interpretar adecuadamente el mensaje. Por ello, suspende momentáneamente la enunciación y, una vez que ha informado a su interlocutor y le ha dado las claves precisas para que éste pueda establecer la adecuada referencia del mensaje, continúa la emisión ${ }^{27}$ :

- ...pues me enfadé un poco porque no había hablado de que la partida... es que algunos domingos se va a jugar al mus a donde José, el de Córdoba, bueno, me voy a buscarle a las siete al bar de José y resulta que se habían ido a jugar la partida al casino. ¡Ya ves tú qué ocurrencias!.

- A: ¿Y dices que te gusta el vino ese?

B: Hombre, no está muy malo; prefiero el, el de.... lo que pasa es que es que mi primo está ahora de representante de vinos en toda esta zona y me los trae bien de precio...., no sé.., casi es mejor el Riberal, de la zona de la ribera, pero de Burgos.

Puede suceder que, debido a la información intercalada, falle la coherencia sintáctica entre la parte inicial y la que se ha recodificado; sin embargo, la conexión temática entre ambas partes siempre se mantiene, el motivo argumental se vuelve a recuperar ${ }^{28}$, por ello el enunciado puede ser perfectamente interpretado por el interlocutor.

De nuevo, las diferencias entre las construcciones fragmentadas y los enunciados recodificados son visibles en todos los estratos lingüísticos. Aunque momentáneamente se produce una suspensión en la línea melódica de los E.R, el abandono no se consuma, puesto que al final presentan el tonema correspondiente (cadencia, anticadencia, etc.). Desde el punto de vista de la sintaxis formal, se trata de secuencias acabadas cuya naturaleza puede ser determinada en bastantes casos; no obstante, algunas resultan agramaticales, en términos estrictamente sintácticos, ya que presentan desviaciones e incorrecciones; pero no por ello dejan de funcionar como unidades comunicativas plenas, puesto que, como se ha indicado, se mantiene en todo momento la coherencia textual, la conexión temática que une las partes aparentemente desgajadas. Es decir, la distorsión sintáctica y la alteración de la linealidad discursiva que manifiestan algunas secuencias no afecta a su consideración pragmática como enunciados.

\footnotetext{
27. Sobre este punto se puede consultar, en la obra citada de A.Vigara: Morfosintaxis..., el epígrafe Expansión. Ampliaciones de la información, pp.420-422.

28. M.J.Bedmar: "El anacoluto..., p.78, indica que, en estos casos, después de producirse la distorsión sintáctica, se recupera nuevamente el tema abandonado, lo que preserva la coherencia textual.
} 
